Correspondence

Darío Ortiz de Orué Lucana

ortiz@biologie.uni-osnabrueck.de

Received 24 June 2005

Revised 20 July 2005

Accepted 26 July 2005

\section{Identification of a novel two-component system SenS/SenR modulating the production of the catalase-peroxidase CpeB and the haem-binding protein HbpS in Streptomyces reticuli}

\author{
Darío Ortiz de Orué Lucana, Peijian Zou, Marc Nierhaus \\ and Hildgund Schrempf \\ FB Biologie/Chemie, Universität Osnabrück, Barbarastr. 11, D-49069 Osnabrück, Germany
}

\begin{abstract}
The Gram-positive soil bacterium and cellulose degrader Streptomyces reticuli synthesizes the mycelium-associated enzyme $\mathrm{CpeB}$, which displays haem-dependent catalase and peroxidase activity, as well as haem-independent manganese-peroxidase activity. The expression of the furS-cpeB operon depends on the redox regulator FurS and the presence of the haem-binding protein $\mathrm{HbpS}$. Upstream of $h b p S$, the neighbouring senS and senR genes were identified. SenS is a sensor histidine kinase with five predicted $\mathrm{N}$-terminally located transmembrane domains. SenR is the corresponding response regulator with a C-terminal DNA-binding motif. Comparative transcriptional and biochemical studies with a designed $S$. reticuli senS/senR chromosomal disruption mutant and a set of constructed Streptomyces lividans transformants showed that the presence of the novel two-component system SenS/SenR negatively modulates the expression of the furS-cpeB operon and the $h b p S$ gene. The presence of SenS/SenR enhances considerably the resistance of $S$. reticuli to haemin and the redox-cycling compound plumbagin, suggesting that this system could participate directly or indirectly in the sensing of redox changes.

Epitope-tagged HbpS (obtained from an Escherichia coli transformant) as well as the native $S$. reticuli $\mathrm{HbpS}$ interact in vitro specifically with the purified SenS fusion protein. On the basis of these findings, together with data deduced from the S. reticuli $h b p S$ mutant strain, HbpS is suggested to act as an accessory protein that communicates with the sensor protein to modulate the corresponding regulatory cascade. Interestingly, close and distant homologues, respectively, of the SenS/SenR system are encoded within the Streptomyces coelicolor A3(2) and Streptomyces avermitilis genomes, but not within other known bacterial genomes. Hence the SenS/SenR system appears to be confined to streptomycetes.
\end{abstract}

\section{INTRODUCTION}

Streptomyces species are found worldwide in soil, exhibit a complex developmental life cycle and are important in soil ecology. These bacteria are metabolically diverse and utilize many carbon sources, including sugars, amino acids, organic acids, aromatic compounds and diverse polymers. The cellulose degrader Streptomyces reticuli has been found to produce a mycelia-associated, haem-containing enzyme (CpeB), which exhibits a catalase-peroxidase activity with broad substrate specificity and manganese-peroxidase activity (Zou \& Schrempf, 2000). The cpeB gene and the regulator gene furS form an operon, and its transcription is regulated by the FurS protein in a redox-dependent fashion

Abbreviations: aa, amino acid; MW, molecular weight; RR, response regulator; SK, sensor kinase; WT, wild-type.
(Ortiz de Orué Lucana \& Schrempf, 2000). The thiol form of FurS contains one zinc ion per monomer and binds in this state to its cognate operator upstream of the furS gene. Oxidation of $\mathrm{SH}$ groups within FurS induces $\mathrm{Zn}^{2+}$ release (Ortiz de Orué Lucana et al., 2003). Downstream of the cpeB gene, the $h b p S$ gene is located in an opposite transcriptional orientation (Fig. 1; Ortiz de Orué Lucana et al., 2004). Comparative physiological, biochemical and immunological studies have revealed that $\mathrm{HbpS}$ is extracellularly located and presents a new haem-binding protein type from Streptomyces.

Since Streptomyces species are soil-dwelling organisms, they need to respond to highly variable conditions. Bacterial adaptation to a wide variety of environmental stimuli is accomplished through the coordinated regulation of many different signal-processing pathways. Many different 


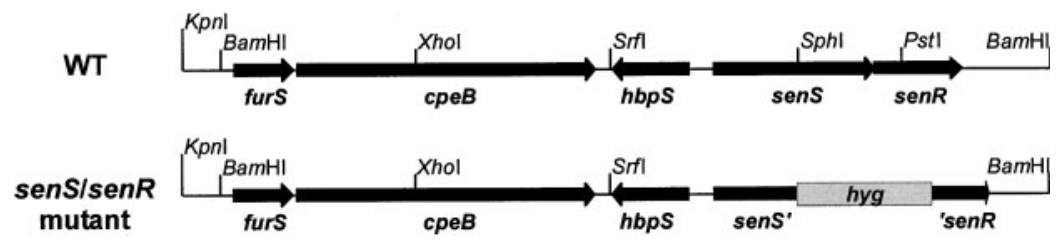

Fig. 1. Restriction and genetic map of a $\mathrm{Kpnl-BamHI}$ fragment on the chromosome of $S$. reticuli strains. The relative positions of the furS-cpeB operon and hbpS gene are presented. The WT genome contains intact senS and senR. The senS/senR mutant has a deleted senS (sen $S^{\prime}$ ) followed by a hygromycin-resistance cassette (hyg) and a deleted senR ('senR). The Srfl-BamHI fragment is present in plasmid pUBB1 (Zou et al., 1999).

bacterial systems for signal transduction comprise a twocomponent structure: a sensor kinase (SK), which is an autophosphorylating histidine protein kinase, and a response regulator (RR), which becomes activated by phosphorylation (Parkinson \& Kofoid, 1992; Pao \& Saier, 1995). The N-terminal part of the SK contains an input domain, and the C-terminal portion comprises a transmitter module with several blocks of amino acid residues which are conserved among SKs. The RR has a receiver domain (generally at its $\mathrm{N}$-terminus) and contains conserved amino acids that define its membership within the response-regulator family. The receiver domain catalyses the transfer of a phosphoryl group from the histidine of the corresponding SK to its conserved aspartic acid residue. The phosphorylation state of the receiver modulates the activity of a unique C-terminally arranged output domain, commonly a transcriptional regulator, eliciting an adaptive response (for a review, see Parkinson, 1993).

The exploration of the Streptomyces coelicolor A3(2) genomic sequences has led to the identification of 84 genes which could encode SKs and 80 genes for RRs (Hutchings et al., 2004). In comparison, an analysis of the complete sequence of the Bacillus subtilis chromosome revealed the presence of 36 genes for putative SKs and 34 genes encoding putative RRs (Fabret et al., 1999). The genome of the Gram-negative bacterium Escherichia coli encodes 32 SKs and 23 RRs, and five hybrid SKs (Mizuno, 1997). The large number of different two-component systems within Streptomyces species appears to reflect their responsiveness to a wide range of environmental stimuli in their rapidly changing habitat. To date, however, only a few two-component systems have been investigated experimentally: the ChiS/ChiR (Streptomyces thermoviolaceus OPC520) system is required for the formation of a chitinase (Tsujibo et al., 1999); the AbsA1/AbsA2 system of $S$. coelicolor A3(2) negatively regulates the production of several antibiotics (Brian et al., 1996; Sheeler et al., 2005); the PhoR/PhoP system from Streptomyces lividans is implicated in the regulation of a high-affinity phosphate transporter and in the production of actinorhodin and undecylprodigiosin (Sola-Landa et al., 2003); the VanR/VanS system from S. coelicolor A3(2) activates the expression of vancomycin resistance (Hong et al., 2004); and the CutR/S system
(S. lividans) negatively affects the synthesis of actinorhodin (Chang et al., 1996).

In this report we describe the identification of genes for a novel two-component system named SenS/SenR from $S$. reticuli. Comparative genetic and biochemical experiments revealed that SenS/SenR is important to modulate the level of FurS, CpeB and HbpS.

\section{METHODS}

Bacterial strains, plasmids, media and culture conditions. $S$. reticuli Tü45 (H. Zähner, Tübingen, Germany) and S. lividans 66 (D. A. Hopwood, John Innes Institute, Norwich, UK) were used. The plasmid pUC18 (Sambrook et al., 1989) was a gift from J. Messing (State University of New Jersey, Piscataway, USA). The E. coli strains DH5 $\alpha$ (Villarejo et al., 1972), M15 (pREP4) (Qiagen) and XL-1 Blue (Loenen \& Blattner, 1983), and the plasmids pWHM3 (Vara et al., 1989), pQE30 (Qiagen) and pASK-IBA7+ (IBA, Göttingen, Germany) were employed for routine cloning purposes (Table 1). The constructs pUKS10, pUBB1 (pUC18 derivatives; Table 1) and pWKS10 (a pWHM3 derivative; Table 1), all of which contain the furS-cpeB operon, have been described previously (Zou et al., 1999; Ortiz de Orué Lucana \& Schrempf, 2000). In addition, plasmids were constructed (Table 1). For cultivation of S. reticuli and S. lividans, complete or minimal media (Schlochtermeier et al., 1992) supplemented with the indicated carbon source were used. Suspensions of spores were made as described elsewhere (Hopwood et al., 1985). Depending on the purpose of the experiments, cultures were grown in baffled Erlenmeyer flasks containing 5-200 $\mathrm{ml}$ on a rotary shaker for 1-4 days. For cultivation of S. reticuli strains on solid media, R2 medium (without sucrose) was used (Hopwood et al., 1985). E. coli strains were grown in LB medium at 37 or $16^{\circ} \mathrm{C}$ (Sambrook et al., 1989).

Chemicals and enzymes. Chemicals for SDS gel electrophoresis were obtained from Serva. Molecular weight (MW) markers, diamide, haemin and plumbagin were supplied by Sigma. Hydrogen peroxide $(30 \%, w / v)$ was bought from Merck. Restriction enzymes, T4 ligase and DNA polymerase for PCR were obtained from Roche, New England Biolabs or Promega.

Isolation of DNA, transformations and hybridization experiments. Chromosomal DNA of $S$. reticuli strains was isolated after growth in a sucrose-containing complete medium for 2 days (Schlochtermeier et al., 1992). Plasmids were isolated from E. coli with the aid of a mini plasmid kit (Qiagen). E. coli DH5 $\alpha$, XL-1 Blue and M15 (pREP4) were transformed with plasmid DNA by electroporation (Dower et al., 1988). S. lividans protoplasts were transformed and regenerated as described by Hopwood et al. (1985). Transformants were selected using an overlay of $2 \mathrm{ml} 0 \cdot 4 \%$ agarose 
Table 1. Plasmids and relevant properties

$a m p^{\mathrm{r}}$, ampicillin resistance gene; $t s r^{\mathrm{r}}$, thiostrepton resistance gene; $h y g^{\mathrm{r}}$, hygromycin resistance gene.

\begin{tabular}{|c|c|c|}
\hline Plasmid & Relevant properties & Source or reference \\
\hline \multicolumn{3}{|c|}{ E. coli plasmids } \\
\hline pUBB1 & $\begin{array}{l}\text { pUC18 derivative carrying furS, cpeB, hbpS, } \\
\operatorname{sen} S, \operatorname{sen} R \text { and } a m p^{\mathrm{r}}\end{array}$ & Zou et al. (1999) \\
\hline pUKS10 & $\begin{array}{l}\text { pUBB } 1 \text { derivative containing furS, cpeB, } \\
h b p S \text { and } a m p^{\mathrm{r}}\end{array}$ & Zou et al. (1999) \\
\hline pUS1 & $\begin{array}{l}\text { pUKS10 derivative carrying truncated } h b p S \text {, } \\
\text { truncated senS and } a m p^{\mathrm{r}}\end{array}$ & This work \\
\hline pUSH1 & pUS1 derivative containing $a m p^{\mathrm{r}}$ and $h y g^{\mathrm{r}}$ & This work \\
\hline pUSHS1 & $\begin{array}{l}\text { pUSH1 derivative used for the generation } \\
\text { of a senS/senR disruption mutant and } \\
\text { containing truncated } h b p S \text {, truncated } \operatorname{sen} S \text {, } \\
\text { truncated } \operatorname{sen} R, h y g^{\mathrm{r}} \text { and } a m p^{\mathrm{r}}\end{array}$ & This work \\
\hline pQE30 & $\begin{array}{l}\text { Expression vector with a multiple cloning site, } \\
\text { six histidine codons for the His-tag and } a m p^{\mathrm{r}}\end{array}$ & Qiagen \\
\hline pQS1 & $\begin{array}{l}\text { pQE30 derivative containing senS downstream } \\
\text { of the codons for the His-tag }\end{array}$ & This work \\
\hline pQH2 & $\begin{array}{l}\text { pQE30 derivative containing } h b p S \text { (without } \\
\text { codons encoding the signal sequence) } \\
\text { downstream of the codons for the His-tag }\end{array}$ & This work \\
\hline pASK-IBA7 + & $\begin{array}{l}\text { Expression vector with a multiple cloning site } \\
\text { and codons for the Strep-tag and } a m p^{\mathrm{r}}\end{array}$ & IBA \\
\hline pASKS1 & $\begin{array}{l}\text { pASK-IBA7 }+ \text { derivative containing senS } \\
\text { downstream of the Strep-tag }\end{array}$ & This work \\
\hline \multicolumn{3}{|c|}{$\begin{array}{l}\text { E. coli/Streptomyces } \\
\text { shuttle vectors }\end{array}$} \\
\hline pWHM3 & Multiple cloning site, $a m p^{\mathrm{r}}$ and $t s r^{\mathrm{r}}$ & Vara et al. (1989) \\
\hline pWKS10 & $\begin{array}{l}\text { pWHM3 derivative carrying the } 4 \cdot 6 \mathrm{~kb} \\
\text { KpnI-SphI fragment from pUKS10 containing } \\
\text { furS, cpeB, hbpS, amp }{ }^{\mathrm{r}} \text { and } t s r^{\mathrm{r}}\end{array}$ & Zou et al. (1999) \\
\hline pWKB1 & $\begin{array}{l}\text { pWKS10 derivative containing furS, cpeB, hbpS, } \\
\operatorname{senS}, \operatorname{sen} R, a m p^{\mathrm{r}} \text { and } t s r^{\mathrm{r}}\end{array}$ & This work \\
\hline
\end{tabular}

supplemented with $400 \mu \mathrm{g}$ thiostrepton leading to a final concentration of $30 \mu \mathrm{g}$ antibiotic $\mathrm{ml}^{-1}$ on the plate (Hopwood et al., 1985). DNA fragments of the restricted $S$. reticuli genome were transferred onto nylon membranes, as described by Sambrook et al. (1989). The hybridization probes were labelled using Klenow enzyme and digoxigenin-11-dUTP (Roche). Hybridization and immunological detection were carried out according to standard procedures (Sambrook et al., 1989).

PCR, DNA sequencing and computer analysis. PCR was performed with Pfu DNA polymerase. Sequencing was done as described by Zou et al. (1999), using the GATC kit (Beck \& Pohl, 1984). Sequence entry, primary analysis and ORF searches were performed using Clone Manager 5.0. Database searches using the PAM120 scoring matrix were carried out with BLAST algorithms (BLASTX, BLASTP and TBLASTN) on the NCBI file server (http:// www.ncbi.nlm.nih.gov/) (Altschul et al., 1997). Multiple sequence alignments were generated by means of the CLUSTAL W (1.74) program (Higgins et al., 1992). Putative Shine-Dalgarno (ribosomebinding) sites (Gold et al., 1981; Strohl, 1992) and signal-peptide cleavage sites (Nielsen et al., 1997) were deduced as described. The prediction of membrane-spanning regions was supported by the TMpred program (ExPASy server; Gasteiger et al., 2003).
RNA isolation and analysis of transcripts. Spores $\left(1 \cdot 2 \times 10^{7}\right)$ of $S$. reticuli [wild-type (WT) and senS/senR mutant] and S. lividans (containing the plasmids pWKB1 or pWKS10) were inoculated into $50 \mathrm{ml}$ complete medium (Schlochtermeier et al., 1992) and grown as a standing culture at $30^{\circ} \mathrm{C}$ for $8 \mathrm{~h}$ and afterwards on a rotary shaker for $16 \mathrm{~h}$. The cultures were washed four times in minimal medium (MM) without supplement. The mycelia from $S$. reticuli strains were suspended in $50 \mathrm{ml} \mathrm{MM}$ supplemented with Avicel ( $1 \%$ final concentration) and cultivated for $6 \mathrm{~h}$. Mycelia from $S$. lividans and its transformants were suspended in the same medium in which Avicel had been replaced by $0.5 \%$ yeast extract (since they cannot use crystalline cellulose as sole carbon source) and cultivation was continued for $14 \mathrm{~h}$. Samples were taken to analyse RNA and proteins (FurS, $\mathrm{CpeB}$ and $\mathrm{HbpS}$ ). Genomic RNA was isolated as previously described (Ortiz de Orué Lucana \& Schrempf, 2000), electrophoretically separated on $2 \%$ agarose gels containing $2 \%$ formamide and $1 \times$ MOPS buffer, and subsequently transferred to a positively charged nylon membrane. For DNA-RNA hybridizations, furS and $h b p S$ probes were radioactively labelled with the 'Rediprime DNA labelling system' (Amersham) using Klenow polymerase and $\left[{ }^{32} \mathrm{P}\right] \mathrm{dCTP}$. Prior to this procedure, the unlabelled probe had been obtained by amplifying DNA regions corresponding to furS and hbpS, respectively, with the primer combinations Furl 
(5'-GGCCGCATGCCCGCCTCCCCGACACCG-3') and Fur2 (5' GGAAGCTTCCGAACTGTGCGGAACTCG-3'), and HBP6 (5'-CAA CGGATCCGACACCACGGAGGCC-3') and HBP7 (5'-GGGCAAGC TTGTGGCCGAGCACGG-3'). Following incubation at $64{ }^{\circ} \mathrm{C}$, the membranes were washed as described previously (Ortiz de Orué Lucana \& Schrempf, 2000) and then subjected to autoradiography. The corresponding transcript signals were quantified by comparing their intensities using 'Gel-Pro Analyser' software (INTAS, Germany).

Cloning of genes in $\boldsymbol{E}$. coli. The longer Srfl-EcoRI fragment (comprising hbpS, senS and senR) of plasmid pUBB1 (Zou et al., 1999) (Table 1) was ligated with the shorter Srfl-EcoRI DNA fragment (containing furS and cpeB) of plasmid pWKS10 (Zou et al., 1999). The obtained plasmid was named pWKB1 (Table 1). The senS-coding region of pWKB1 was amplified by PCR using the primers: SenS1, 5'-CTTTGGATCCGTGCCGACGGTGGCCGTAC-3', consisting of an BamHI $\overline{\text { restriction }}$ site (underlined), followed by the sequence encoding the N-terminal amino acids of SenS; and SenS2, 5'-GTATAAGCTTTCATCTCGGCTCCAACG-3', determining the C-terminal amino acids of SenS, followed by the HindIII restriction site (underlined). The PCR product was digested with BamHI and HindIII and ligated with BamHI/HindIII-digested pQE30 (Table 1) or BamHI/HindIII-digested pASK-IBA7 + (Table 1). The resulting plasmids PQS1 or pASKS1 (Table 1), respectively, were transformed into E. coli XL-1 Blue. Having sequenced the plasmids, the correctness of the designed senS gene and its in-frame fusion with the Histag or Strep-tag codons were confirmed.

The $h b p S$-coding region (without the codons encoding the signal peptide) of the above-described construct pWKB1 was amplified by PCR with primers: HBP6, 5'-CAACGGATCCGACACCACGGAGGCC3', consisting of a BamHI restriction site (underlined), followed by the sequence encoding the $\mathrm{N}$-terminal amino acids of the mature $\mathrm{HbpS}$ (without the signal peptide); and HBP7, 5'-GGGCAAGCTTGTGGCCG AGCACGG-3', determining the C-terminal amino acids of $\mathrm{HbpS}$, followed by the HindIII restriction site (underlined). The PCR product was digested with BamHI and HindIII, ligated withBamHI/HindIIIcleaved pQE30 (Table 1) and subsequently transformed into E. coli XL-1 Blue. Having sequenced the resulting plasmid $\mathrm{pQH} 2$, the correctness of the $h b p S$ gene and its in-frame fusion with the His-tag codons were confirmed.

Purification of the fusion proteins and generation of antibodies. Each of the above-described plasmids pQS1 and pQH2 was transformed into E. coli M15 (pREP4). A selected transformant containing the pQS1 plasmid was inoculated in LB medium with ampicillin $\left(100 \mu \mathrm{g} \mathrm{ml}^{-1}\right)$ and kanamycin $\left(50 \mu \mathrm{g} \mathrm{ml}^{-1}\right)$. Cultivation was carried out at $16^{\circ} \mathrm{C}$ to avoid the formation of inclusion bodies, which had been found to occur at higher temperatures (data not shown). The synthesis of the His-tag-SenS fusion protein was induced by the addition of $0.5 \mathrm{mM}$ IPTG after the culture had reached an $\mathrm{OD}_{600}$ of $0 \cdot 6$. The cells were grown for $8 \mathrm{~h}$, harvested, washed with chilled solution A $(10 \mathrm{mM}$ HEPES, $60 \mathrm{mM} \mathrm{KCl}$, $\mathrm{pH} \mathrm{8.0)} \mathrm{and} \mathrm{disrupted} \mathrm{by} \mathrm{ultrasonication} \mathrm{(Branson} \mathrm{sonifier,}$ $5 \times 10 \mathrm{~s}$, with $10 \mathrm{~s}$ intervals). Purification of the fusion protein was performed under native conditions using $\mathrm{Ni}^{2+}$ affinity chromatography according to the instructions of the manufacturer (Qiagen). From 11 of culture, $0.05 \mathrm{mg}$ His-tag-SenS was obtained. For further purification and concentration, the His-tag-SenS protein was recovered from a preparative SDS-polyacrylamide gel by using an electro-elution cell according to the instructions of the manufacturer (Bio-Rad). The purified protein $(150 \mu \mathrm{g})$ was used to generate antibodies in guinea pigs (EUROGENTEC, Belgium). The antisera were then directly used for protein-protein interaction studies (see below).

E. coli M15 (pREP4, pQH2) was cultivated in LB medium with ampicillin $\left(100 \mu \mathrm{g} \mathrm{ml}^{-1}\right)$ and kanamycin $\left(50 \mu \mathrm{g} \mathrm{ml}^{-1}\right)$ at $37^{\circ} \mathrm{C}$. After the culture had reached an $\mathrm{OD}_{600}$ of $0 \cdot 6$, the synthesis of His-tag-HbpS was induced by adding $0.5 \mathrm{mM}$ IPTG and the cultivation was continued for $3 \mathrm{~h}$. His-tag-HbpS was purified from the cytoplasm by affinity chromatography, as described previously (Ortiz de Orué Lucana \& Schrempf, 2000). From 11 of culture, 2 mg His-tag-HbpS was obtained.

SenS was purified as a Strep-tag fusion protein from an E. coli XL-1 Blue transformant (carrying the plasmid pASKS1 containing the senS gene), which had been cultivated in LB medium containing ampicillin $\left(100 \mu \mathrm{g} \mathrm{ml}^{-1}\right)$ at $16^{\circ} \mathrm{C}$. The synthesis of the protein was induced (at an $\mathrm{OD}_{600}$ of $0 \cdot 6$ ) by adding anhydrotetracycline $\left(200 \mathrm{ng} \mathrm{ml}^{-1}\right.$ ). The produced protein was purified from cleared cell lysates using streptactin affinity chromatography, according to the instructions of the manufacturer (IBA). Per 11 of culture, $0 \cdot 1 \mathrm{mg}$ Strep-tag-SenS was obtained.

Protein-protein interactions. The Strep-tag-SenS fusion protein was used to test the interaction with $\mathrm{HbpS}$ by affinity chromatography. Firstly, Strep-tag-SenS was purified as described above and dialysed against buffer W $(100 \mathrm{mM}$ Tris/ $\mathrm{HCl}, \mathrm{pH} 8 \cdot 0,150 \mathrm{mM} \mathrm{NaCl})$ and loaded onto a streptactin column. Non-specifically bound proteins were washed off and the Strep-tag-SenS protein was kept immobilized. In parallel, the synthesis of His-tag-HbpS was induced in the recombinant E. coli M15 (pREP4, pQH2). Its cytoplasmic extract (comprising His-tag-HbpS) and concentrated proteins of the culture filtrate from $S$. reticuli were then separately loaded onto the streptactin column containing Strep-tag-SenS. As a control, the protein extracts were loaded onto the streptactin column without immobilized Strep-tag-SenS. Each column was then washed five times with buffer $\mathrm{W}$, and bound proteins were eluted using desthiobiotin according to the instructions of the manufacturer (IBA).

For affinity blotting (named 'Far Western' or 'Blot overlay analysis'; Hall, 2004) $1 \mu \mathrm{g}$ of the purified proteins (His-tag-SenS and His-tag$\mathrm{HbpS}$ ) was fractionated separately via SDS-PAGE, transferred to a PVDF membrane and preincubated for $2 \mathrm{~h}$ in PBS buffer $(40 \mathrm{mM}$ disodium hydrogen phosphate, $8 \mathrm{mM}$ sodium dihydrogen phosphate, $150 \mathrm{mM}$ sodium chloride, $\mathrm{pH} 7 \cdot 4$ ) containing $5 \%$ skimmed milk powder. Purified His-tag-SenS was added in PBS buffer to a final concentration of $1 \mu \mathrm{g} \mathrm{ml}^{-1}$ and incubated for $16 \mathrm{~h}$ at room temperature. As a control, one membrane containing lanes of the transferred proteins was incubated with PBS buffer without the addition of His-tag-SenS. Membranes were then washed three times with PBS buffer and incubated with anti-SenS antibodies in PBS buffer. After treatment with secondary anti-guinea-pig antibodies conjugated with alkaline phosphatase, the membrane was stained with 5-bromo-4chloro-3-indolyl-phosphate and nitro blue tetrazolium (Blake et al., 1984).

Generation of the $S$. reticuli senS/senR disruption mutant. The plasmid pUKS10 (Zou et al., 1999) was digested with BsiWI and SphI. The 1142 bp DNA fragment (containing a portion of $h b p S$ and part of senS; Fig. 3) was treated with Klenow enzyme and then ligated with the vector pUC18, which had been digested with HincII and SphI. The resulting construct was named pUS1 (Table 1). A HindIII fragment $(2 \cdot 3 \mathrm{~kb})$ of a pBR322 derivative with a hygromycin-resistance cassette (hyg) containing terminator sequences (Blondelet-Rouault et al., 1997) was blunt-ended using the Klenow enzyme and ligated with the SphI-digested and blunt-ended pUS1. The resulting plasmid, pUSH1 (Table 1), containing hyg was then digested with HindIII, blunt-ended and ligated with the blunt-ended PstI-PstI fragment (1105 bp) from the pWKB1 plasmid containing part of $\operatorname{sen} R$ and its downstream region (Fig. 3). The ligation mixture was added to electrocompetent E. coli DH5 $\alpha$ cells. Hygromycinresistant E. coli transformants were selected, and the correctness of their plasmid constructs was analysed with restriction enzymes. One of the correct constructs, named pUSHS1, was isolated. A $10 \mu \mathrm{g}$ 
portion thereof was denatured $\left(0.2 \mathrm{M} \mathrm{NaOH}, 10 \mathrm{~min}, 37^{\circ} \mathrm{C}\right)$, chilled on ice and neutralized by rapid addition of $\mathrm{HCl}$. The DNA was then used to transform $50 \mu$ of protoplasts $\left(\sim 10^{9} \mathrm{ml}^{-1}\right)$ generated from $S$. reticuli, which were spread onto osmotically stabilized medium (R2 medium containing $15 \%$ sucrose) and incubated at $30^{\circ} \mathrm{C}$ for $19 \mathrm{~h}$. The plates were overlaid with $2 \mathrm{ml}$ molten agarose $\left(40^{\circ} \mathrm{C}\right)$ containing hygromycin $\left(1 \mathrm{mg} \mathrm{ml}^{-1}\right)$, leading to a final concentration of $75 \mu \mathrm{g}$ antibiotic $\mathrm{ml}^{-1}$ on the plate. Hygromycinresistant colonies were restreaked several times, and then their genomic DNA was analysed with respect to the size of fragments carrying the hygromycin-resistance gene.

Inhibition tests. The sensitivity of $S$. reticuli WT and senS/senR mutant to haemin, $\mathrm{H}_{2} \mathrm{O}_{2}$, the thiol-specific oxidant diamide and the redox-cycling substance plumbagin was determined using a disc inhibition assay. Spores $\left(5 \times 10^{8}\right)$ in a $100 \mu \mathrm{l}$ suspension were added to $3 \mathrm{ml}$ soft agar (Sambrook et al., 1989), poured onto the respective R2 plates and allowed to solidify. On the top of this plate, sterile $6 \mathrm{~mm}$ diameter paper discs (Schleicher \& Schuell) were placed which contained $20 \mu \mathrm{l}$ of each of the following solutions: haemin $(300 \mu \mathrm{M}), \mathrm{H}_{2} \mathrm{O}_{2}(250 \mathrm{mM})$, diamide $(250 \mathrm{mM})$ and plumbagin $(100 \mathrm{mM})$. Plates were incubated overnight at $30^{\circ} \mathrm{C}$ and zones of inhibition were measured.

SDS-PAGE and Western blotting. SDS-PAGE was performed in the presence of $0 \cdot 1 \%$ SDS (Laemmli, 1970). Proteins were separated by $10 \%$ SDS-PAGE and transferred to a PVDF membrane (Sambrook et al., 1989), which was blocked for $1 \mathrm{~h}$ at room temperature with PBS containing $5 \%$ skimmed milk powder and subsequently incubated overnight at $4{ }^{\circ} \mathrm{C}$ with the anti-CpeB antibodies previously described (Zou et al., 1999). After treatment with secondary anti-rabbit antibodies conjugated with alkaline phosphatase, the membrane was stained with 5-bromo-4-chloro-3-indolyl-phosphate and nitro blue tetrazolium (Blake et al., 1984). The corresponding protein signals were quantified by comparing their intensities using 'Gel-Pro Analyser' software (INTAS).

\section{RESULTS}

\section{senS and senR genes encode a novel two- component system}

Sequence analysis of a previously cloned stretch of genomic S. reticuli DNA (within the plasmid pUBB1; Zou et al., 1999) revealed upstream of the $h b p S$ gene the presence of two neighbouring Orfs of $1196 \mathrm{bp}$ and $653 \mathrm{bp}$ (see Fig. 1 and EMBL: Y14336). These were named senS and $\operatorname{sen} R$, respectively. The senS gene is separated by $191 \mathrm{bp}$ from the $h b p S$ gene, which is located in an opposite orientation. The deduced SenS protein has 398 amino acids with a predicted MW of $42 \cdot 2 \mathrm{kDa}$, a theoretical isoelectric point (pI) of 7.96 and five possible membrane-spanning domains (Fig. 2a). Multiple sequence alignments (Fig. 2a) suggested that the deduced protein may encode a histidine kinase (SenS) which carries, in addition to individually conserved amino acids, two shorter regions with several identical amino acids, including two histidine residues (positions 199 and 315) and an asparagine residue (position 311). SenS shares $68 \%$ and $34 \%$ amino acid (aa) identity, respectively, with a putative histidine kinase (OrfS) from S. coelicolor A3(2) and with the described histidine kinase ChrS from Corynebacterium diphtheriae (Schmitt, 1999). Using the sequence alignments (Parkinson, 1993), the histidine residue at position 199 within SenS was predicted to be the phosphorylation site.

The stop codon (TGA) of senS overlaps the start codon of $\operatorname{senR}$ (ATG). The deduced SenR protein has 217 aa, with a predicted MW of $23 \cdot 2 \mathrm{kDa}$ and a theoretical $\mathrm{pI}$ of $6 \cdot 60$. The deduced N-terminal region of SenR shares aspartic acid residues (in positions 19,20,60 and 65), as well as their relative positioning, with characterized RRs, including ChrA (Schmitt, 1999). A phosphoryl group is predicted to be transferable to aspartic acid residue 65 in SenR. The Cterminal region of SenR contains a predicted helix-turnhelix (HTH) (Fig. 2b) which has similarities to members of the HTH_LUXR_FAMILY; thus SenR is probably the RR for the predicted SK SenS. SenR shares the highest $(80 \%)$ aa identity to a putative RR (OrfR) from S. coelicolor A3(2) and $50 \%$ aa identity to the described RR ChrA from $C$. diphtheriae (Schmitt, 1999). The genes chrA and orfR are located downstream of the genes $\operatorname{chrS}$ and orfS, respectively (data not shown), and are predicted to encode the corresponding RRs for ChrS and OrfS, respectively.

\section{Role of SenS/SenR in S. lividans transformants}

The senS and senR genes are located upstream of the $h b p S$ gene encoding the haem-binding protein $\mathrm{HbpS}$ and downstream of the furs-cpeB operon encoding the redoxdependent FurS regulator protein and the haem-containing catalase-peroxidase CpeB. Thus, it has been speculated that SenS and SenR as a two-component system might influence the production of these proteins. Due to the relatively low abundance of FurS, CpeB and HbpS in S. reticuli (Ortiz de Orué Lucana \& Schrempf, 2000; Ortiz de Orué Lucana et al., 2004), the multicopy plasmids pWKS10 containing a truncated senS without $\operatorname{senR}$ (Fig. 3, Table 1) and pWKB1 carrying senS and $\operatorname{sen} R$ (Fig. 3, Table 1) were transformed in S. lividans protoplasts.

Each of the selected transformants containing the correctly designed plasmids was cultivated in minimal medium supplemented with yeast extract, as described in Methods. Interestingly, comparative RNA analysis showed that the amount of furS mRNA (Fig. 4a) and hbpS mRNA (Fig. 4b) was considerably higher in S. lividans containing pWKS10 than in S. lividans with pWKB1. Further immunological studies revealed that $S$. lividans containing pWKS10 produced clearly higher amounts of the proteins FurS (Fig. 4c), CpeB (Fig. 4d) and HbpS (Fig. 4e). The data imply that the $\operatorname{sen} S$ and $\operatorname{sen} R$ genes negatively influence the expression of the furS-cpeB operon and the $h b p S$ gene.

\section{Comparative studies of S. reticuli WT and senS/senR disruption mutant}

To analyse the role of SenS/SenR within the S. reticuli WT strain, the corresponding chromosomal genes were disrupted by insertional inactivation. To achieve this, the plasmid pUSHS1 containing the hygromycin-resistance cassette (hyg) flanked by residual portions of senS and 
(a)

Sens_retic
Orfs_coeli
Chrs_dipht
Sens_retic
Orfs_coeli
Chrs_dipht
Sens_retic
orfs_coeli
Chrs_dipht
Sens_retic
orfs_coeli
Chrs_dipht
Sens_retic
Orfs_coeli
Chrs_dipht
Sens_retic
orfs_coeli
Chrs_dipht
Sens_retic
orfs_coeli
Chrs_dipht
Sens_retic
orfs_coeli
Chrs_dipht

(b)

SenR_retic OrfR_coeli ChrA_dipht

SenR_retic OrfR_coeli ChrA_dipht

SenR_retic OrfR_coeli ChrA_dipht

SenR_retic OrfR_coeli ChrA_dipht
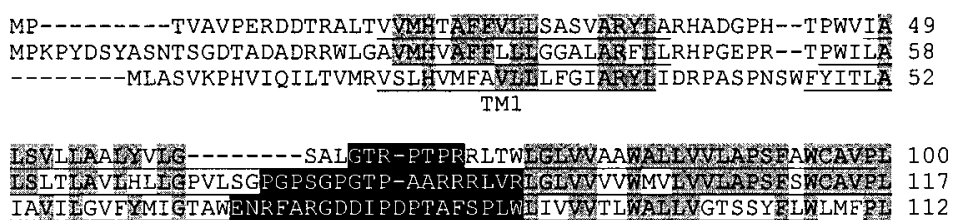
USLT

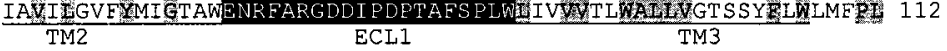

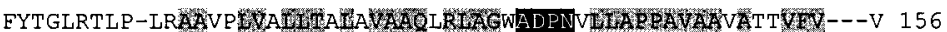

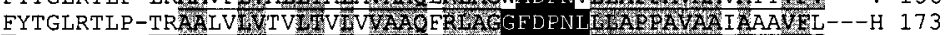
IFVMLHLRHGIQGILGVAS GYAIAIAIPLVTRPADWGPAQAMGPAIGT ESTVIEYGYAT 172

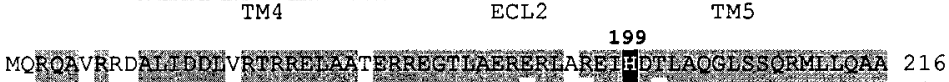

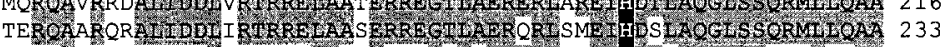
LRNDAQHYRQLAAE

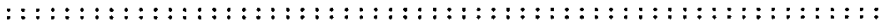

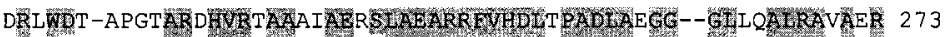

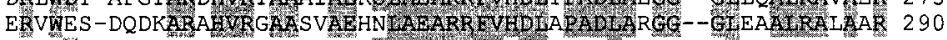

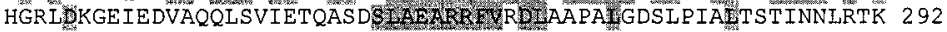

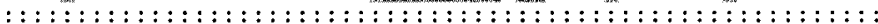

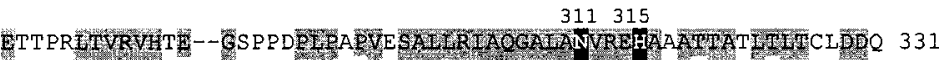

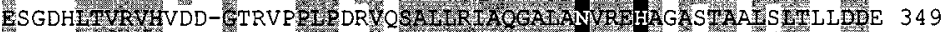

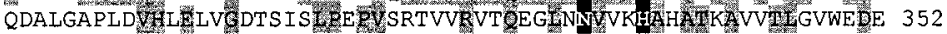
: : : : : : : : : : : : : : : : : : : : : : : : : : : : : : : : : : : : : : : : : : : : : : : : : : : : : : : : : :::: : : : :::

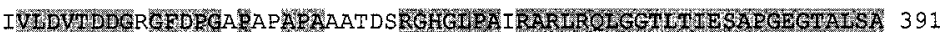

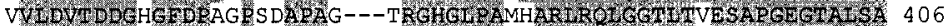

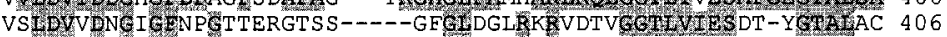

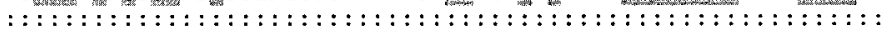

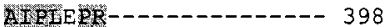

WIPUDNPRTDPADPAGPQEAPR 428

RIPZTSRRETS-D.------ 417

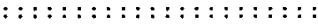
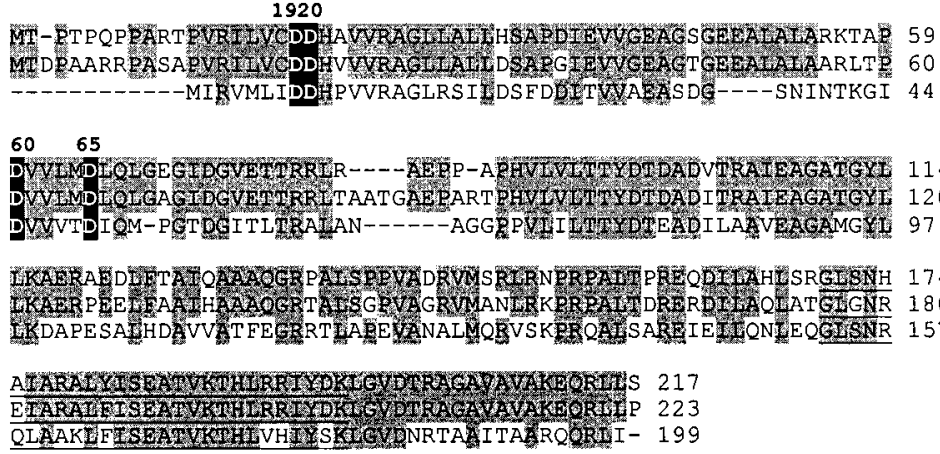

OLA

DNA-binding domain (HTH motif)

Fig. 2. Alignments of comparisons of SenS and SenR with members of other two-component systems. (a) The SenS protein from S. reticuli (SenS_retic; EMBL Y14336) was aligned to the putative sensor kinase OrfS from S. coelicolor (OrfS_coeli; UniProt/TrEMBL Q9KXW6) and the sensor kinase ChrS from C. diphtheriae (ChrS_dipht; EMBL AF161327). The transmembrane domains (TM1-TM5) are underlined. The extracytoplasmic loops (ECL1 and ECL2) are shown in white type on a black background. The cytoplasmic domains are marked with colons. The histidine $(\mathrm{H})$ residues at positions 199 and 315 , as well as the asparagine $(\mathrm{N})$ residue at position 311 in the cytoplasmic domain of SenS and the corresponding positions in OrfS and ChrS are written in bold white type on a black background. (b) The SenR protein from S. reticuli (SenR_retic; EMBL Y14336) has been aligned with the deduced response regulators OrfR from S. coelicolor (OrfR_coeli; UniProt/TrEMBL Q9KXW5) and ChrA from C. diphtheriae (ChrA_dipht; EMBL AF161327). The aspartic acid residues at positions 19, 20, 60 and 65 in SenR and the corresponding ones in OrfR and ChrA are written in bold white type on a black background. The DNA-binding domain is indicated and underlined.

senR was constructed (see Methods and Table 1). The $S$. reticuli WT strain was transformed with the denatured plasmid pUSHS1; subsequently, several hygromycin- resistant colonies were obtained. As revealed by Southern hybridization (data not shown), hyg was found to disrupt the reading frame of senS and senR (Fig. 1), and hence the 


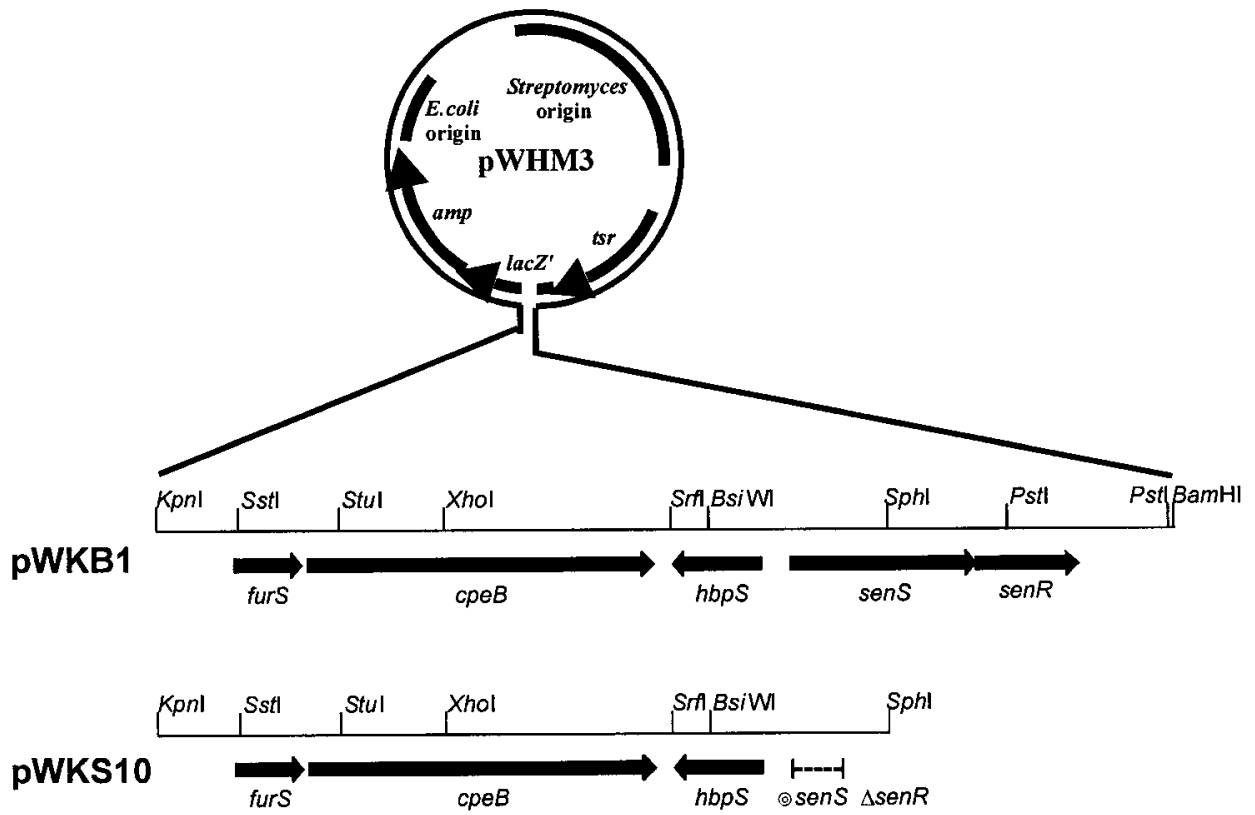

Fig. 3. Characteristics of the plasmids. The plasmids are derived from the bifunctional pWHM3 vector. pWKB1 contains the genes furS, cpeB, hbpS, senS and senR, whereas pWKS10 differs in having a truncated senS (shown by the dashed line) and lacking senR.

\section{S. lividans transformants}
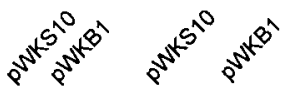

Detection of transcripts

(a)
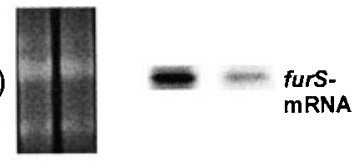

(b)
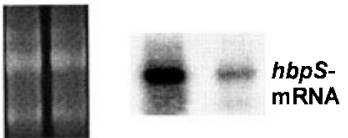

Detection of proteins

(c)

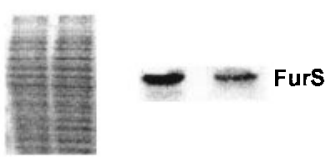

(d)

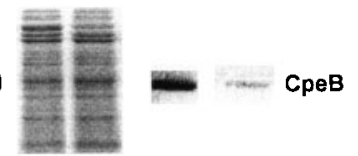

(e)

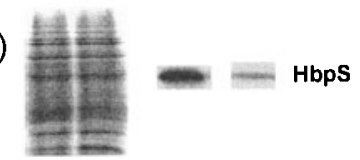

(g)

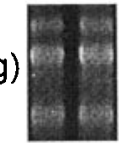

\section{S. reticuli strains}

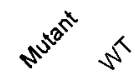

(f)
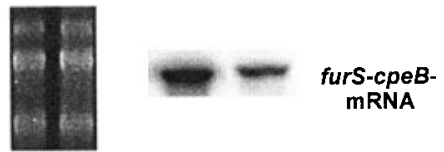

(h)
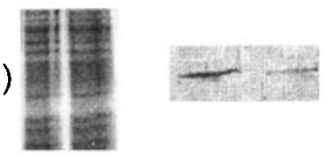

Furs

(i)
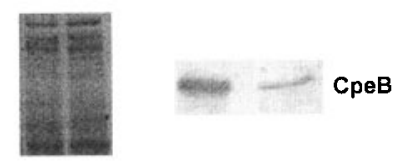

(j)

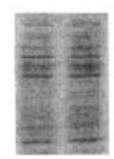

Fig. 4. Analysis of transcripts and gene products in $S$. lividans transformants and $S$. reticuli strains. S. lividans transformants (left) carrying the plasmids pWKS10 and pWKB1 and the S. reticuli senS/senR mutant (right) and S. reticuli WT (right) were cultivated as described in Methods and used for the detection of specific mRNA ( $a, b, f$ and $g$ ) and proteins (c, d, e, h, $i$ and j). Aliquots $(15 \mu \mathrm{g})$ of total RNA were separated by gel electrophoresis ( $a, b, f$ and $g$, left) transferred to a nylon membrane and hybridized with the furS gene (a and $f$, right) or the $h b p S$ gene (b and $\mathrm{g}$, right). Cytoplasmic proteins were precipitated with $\left(\mathrm{NH}_{4}\right)_{2} \mathrm{SO}_{4}$ (fraction $30-60 \%, w / v$ ) and separated by SDS-PAGE followed by Coomassie staining ( $\mathrm{c}$ and $\mathrm{h}$, left), and then analysed by Western blot using anti-FurS antibodies (c and $h$, right). Aliquots of released myceliaassociated proteins ( $d$ and $i$, left) were tested for the presence of $\mathrm{CpeB}$ by Western blot analysis using anti-CpeB antibodies ( $\mathrm{d}$ and $\mathrm{i}$, right). Precipitated proteins from the culture filtrates were separated by SDS-PAGE followed by Coomassie staining (e and $\mathrm{j}$, left) and analysed for the presence of HbpS (Western blot) using anti-HbpS antibodies (e and j, right). 
independent colonies must have arisen by double crossover. The characteristics of substrate and aerial mycelia, as well as spore formation, were identical in the mutant and WT strains.

Further comparative studies were performed with a representative $S$. reticuli senS/senR mutant and the WT strain. Hybridization studies (Northern blot) showed that among equivalent quantities of total RNA, the level (about 12-fold; for estimation see Methods) of specific furS-cpeB transcripts was enhanced (Fig. 4f) and the level (about sevenfold; for estimation see Methods) of specific $h b p S$ transcripts was enhanced (Fig. 4g) in the S. reticuli senS/senR disruption mutant. Immunological studies using anti-FurS antibodies revealed that the proteins of the cytoplasmic fraction [enriched by fractionated $\left(\mathrm{NH}_{4}\right)_{2} \mathrm{SO}_{4}$ precipitation] from the $S$. reticuli senS/senR disruption mutant contained higher amounts (about eightfold; for estimation see Methods) of FurS than the WT strain (Fig. 4h). As detected with anti-CpeB antibodies, the $S$. reticuli senS/senR mutant produced considerably higher quantities (about eightfold; for estimation see Methods) of the mycelium-associated CpeB than the WT strain (Fig. 4i). Further immunological studies using anti-HbpS antibodies revealed that the proteins of the culture filtrate [enriched by $\left(\mathrm{NH}_{4}\right)_{2} \mathrm{SO}_{4}$ precipitation] of the $S$. reticuli senS/sen $R$ disruption mutant contained considerably higher amounts (about eightfold; for estimation see Methods) of HbpS than those of the WT (Fig. 4j). These data clearly revealed that the presence of the two-component system SenS/SenR dictates relatively low levels of FurS, CpeB and HbpS within S. reticuli.

\section{S. reticuli WT and the senS/senR mutant differ in sensitivity to different compounds}

As shown recently, the production of $\mathrm{HbpS}$ in S. reticuli WT is induced by haemin (the $\mathrm{Fe}^{3+}$ oxidation product of haem) (Ortiz de Orué Lucana et al., 2004). Haemin possesses significant antibacterial activity that is augmented by the presence of physiological concentrations of hydrogen peroxide or a reducing agent (Stojiljkovic et al., 2001). Compared to the WT strain, the relative sensitivities of the mutant strain to haemin $(300 \mu \mathrm{M})$ and the redox-cycling substance plumbagin $(100 \mathrm{mM})$ showed increases of 66 and $41 \%$, respectively (Table 2). The presence of $\mathrm{H}_{2} \mathrm{O}_{2}$ $(250 \mathrm{mM})$ or the thiol-specific oxidant diamide $(250 \mathrm{mM})$ led to a relatively small enhancement of sensitivity (26 and $12 \%$, respectively; Table 2 ).

\section{SenS interacts with HbpS}

Our previous data have shown that the haem-binding protein HbpS is secreted (Ortiz de Orué Lucana et al., 2004). Due to the relative positioning of $h b p S$ and $\operatorname{sen} S / \operatorname{sen} R$ (see Fig. 1) and the above outlined results we considered the possibility that $\mathrm{HbpS}$ could interact with SenS and therefore could participate in the signal transduction cascade. To obtain SenS and HbpS, the corresponding genes were fused with codons encoding a His-tag or a Strep-tag (only in the
Table 2. Sensitivity of $S$. reticuli strains to haemin, plumbagin, $\mathrm{H}_{2} \mathrm{O}_{2}$ and diamide

\begin{tabular}{|c|c|c|c|}
\hline \multirow[t]{2}{*}{$\begin{array}{l}\text { Substance } \\
\text { (concentration) }\end{array}$} & \multicolumn{2}{|c|}{$\begin{array}{l}\text { Diameter of zone } \\
\text { of inhibition } \\
(\mathrm{mm})^{\star}\end{array}$} & \multirow[t]{2}{*}{$\begin{array}{c}\text { Relative increase } \\
\text { of sensitivity for the } \\
\text { senS/senR mutant }\end{array}$} \\
\hline & WT & $\begin{array}{c}\text { senS/senR } \\
\text { mutant }\end{array}$ & \\
\hline Haemin $(300 \mu \mathrm{M})$ & 12 & 20 & $66 \%$ \\
\hline Plumbagin (100 mM) & 24 & 34 & $41 \%$ \\
\hline $\mathrm{H}_{2} \mathrm{O}_{2}(250 \mathrm{mM})$ & 30 & 38 & $26 \%$ \\
\hline Diamide $(250 \mathrm{mM})$ & 32 & 36 & $12 \%$ \\
\hline
\end{tabular}

*The assays were repeated four times.

case of senS) (see Methods) located on a pQE30 or pASKIBA7 + vector, respectively. Having optimized expression conditions (see Methods), each of the fusion proteins was isolated in soluble form from the cytoplasm of the corresponding E. coli transformant. The Strep-tag-SenS fusion protein (data not shown) was immobilized on the streptactin resin. Proteins from the cytoplasm of the induced E. coli M15 (pREP4, pQH2) producing the His-tag-HbpS were added onto this resin. Detachment (with desthiobiotin) of Strep-tag-SenS led to an additional release of $\mathrm{HbpS}$ but no other proteins (Fig. 5a). As a control, the same procedure was done in the absence of Strep-tag-SenS; in this case, no His-tag-HbpS was released (data not shown). Using the same strategy, the Strep-tag-SenS fusion protein was shown to interact with an extracellular $S$. reticuli protein $(16 \mathrm{kDa}$; Fig. 5b) that reacts with the anti-HbpS antibody (Fig. 5c).

For affinity blotting, each of the purified proteins (Fig. 5d) was separated by SDS-PAGE and transferred to PVDF membranes. One strip was then incubated with the purified His-tag-SenS protein (Fig. 5e) and the second one (Fig. 5f) without additional His-tag-SenS. Having washed the strips (to remove unbound His-tag-SenS), the results of immunological studies (with anti-SenS antibodies) revealed that the immobilized His-tag-HbpS interacts with His-tag-SenS protein (Fig. 5e). As expected, no cross-reactivity was obtained with HbpS alone (Fig. 5f). Taken together, the presented results clearly show that the HbpS protein interacts in vitro specifically with the sensor kinase SenS.

\section{DISCUSSION}

The studies described here provide evidence that the novel two-component system SenS/SenR influences the production of the proteins FurS, $\mathrm{CpeB}$ and $\mathrm{HbpS}$ by S. reticuli. The deduced SenS shares some similar features with known SKs. Among the characterized SKs, ChrS (from $C$. diphtheriae; Schmitt, 1999) is most related (34\% aa identity). SenS shows high aa identity $(68 \%)$ to a so-far-uncharacterized protein (OrfS) encoded within the $S$. coelicolor A3(2) genome (Bentley et al., 2002) and $40 \%$ aa identity with one 
(a)

(b)

(c)
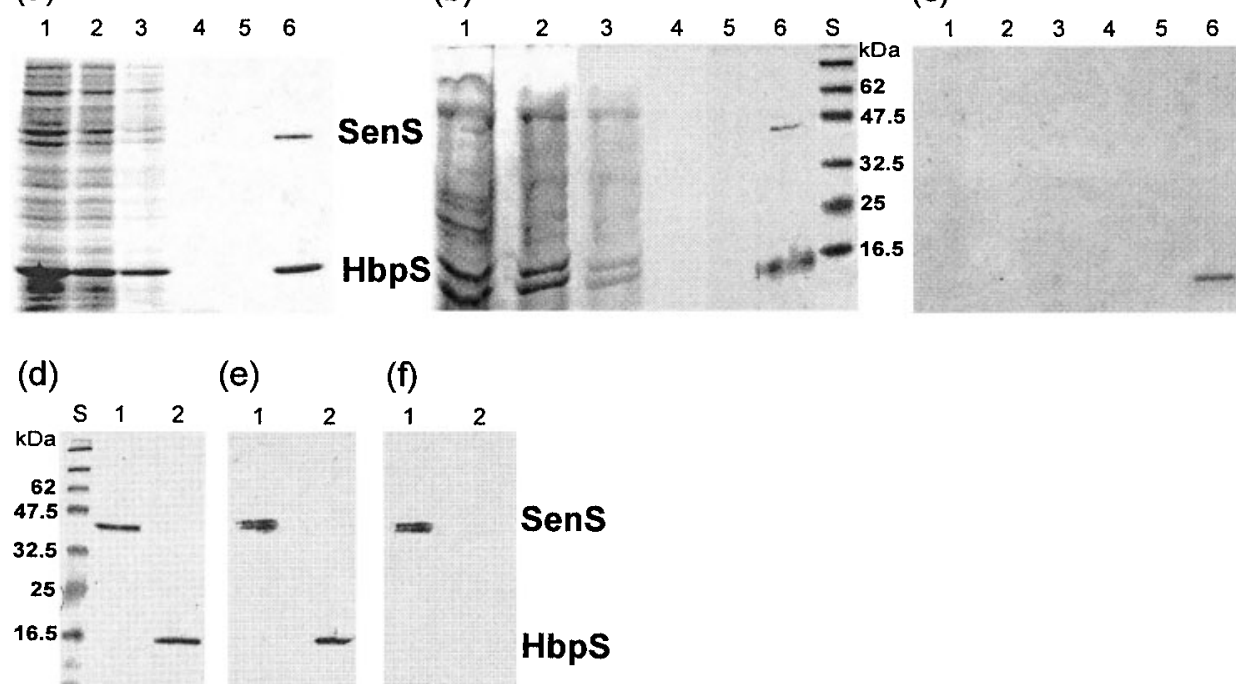

Fig. 5. Interaction between SenS and HbpS. Soluble protein extracts containing His-tag-HbpS obtained from E. coli M15 (pREP4, pQH2) (a) and precipitated extracellular proteins from S. reticuli WT (b and c) were loaded onto a streptactin column containing the isolated Strep-tag-SenS. Fractions containing unbound proteins $(a, b$ and $c$, lane 1$)$ and the four wash fractions ( $a, b$ and $c$, lanes 2-5) were collected. Bound proteins were eluted with buffer $W$ containing $2.5 \mathrm{mM}$ desthiobiotin ( $\mathrm{a}, \mathrm{b}$ and c, lane 6). Samples were subjected to SDS-PAGE and stained with Coomassie brilliant blue (a) or silver (b). The separated proteins from (b) were also transferred onto a PVDF membrane and incubated with anti-HbpS antibodies (c). (d-f) Affinity blotting studies. (d) His-tag-SenS (lane 1) and His-tag-HbpS (lane 2) were isolated by $\mathrm{Ni}^{2+}-\mathrm{NTA}$ affinity chromatography as described in Methods, subjected to SDS-PAGE and stained with Coomassie brilliant blue. (e) His-tag-SenS (lane 1) and Histag-HbpS (lane 2) were separated by SDS-PAGE, transferred to a PVDF membrane and incubated with His-tag-SenS. Bound His-tag-SenS was detected with anti-SenS antibody. (f) As a control, the same procedure [see (e)] was repeated, but the incubation with His-tag-SenS was left out. The double SenS band (e and f, lane 1) represents the complete protein and a slightly $\mathrm{N}$-terminally truncated form.

encoded in the S. avermitilis genome (Ikeda et al., 2003). SenS, ChrS and OrfS contain five predicted transmembrane domains. The deduced extracytoplasmic loop regions of SenS and ChrS do not share relevant aa identities, and their predicted membrane-spanning regions have in common some short, related motifs (Fig. 2a). Extracytoplasmic loop regions between transmembrane helices have been proposed to be involved in the detection of environmental stimuli by other SKs (Parkinson \& Kofoid, 1992), and it is also possible that regions between the putative membrane-spanning regions play a role. The cytoplasmic domains of SenS and ChrS show a few related motifs (Fig. 2a). It has been assumed that the SK ChrS is involved in the detection of haem and the transduction of this signal, via a phosphotransfer mechanism, to the RR ChrA (Schmitt, 1999).

The central part of SenS contains a histidine residue (H199), which is predicted to be phosphorylated, as its position corresponds to that of other SKs. The SKs have been classified in five groups (I, II, IIIA, IIIB and IV) according to the relative positioning of the 16 aa residues surrounding the conserved histidine residue (Fabret et al., 1999). Taking these criteria into account, SenS belongs to group II (data not shown). Based on the relatedness of output domains (Fabret et al., 1999), SenR is a member of RR group II. Each known group II SK gene is upstream of the gene encoding the corresponding RR and in the same orientation within the transcription unit. SenR harbours aspartic acid residues (in positions 19, 20,60 and 65), which are conserved among RRs (Baikalov et al., 1996) and which probably form an acid pocket that plays a role in the signal-transduction cascade; thus, the phosphoryl group of SenS is predicted to be transferable to aspartic acid residue (D) 65. The relative organization of the senS gene and the senR gene is identical to that of homologous genes within the S. coelicolor A3(2) genome (Bentley et al., 2002), which, interestingly, are preceded by an uncharacterized gene that is closely related to $h b p S$. However, the furS and cpeB homologues (furA and catC) from S. coelicolor A3(2) are located far apart from the hbpS homologue (Fig. 6a).

The analysis of $S$. reticuli WT, the corresponding $\operatorname{senS} / \operatorname{sen} R$ disruption mutant and the designed S. lividans transformants revealed that the presence of SenS/SenR leads to a significant reduction of furS, $c p e B$ and $h b p S$ transcript levels and of the corresponding proteins. Interestingly, the $S$. reticuli mutant strain exhibits an increased sensitivity to haemin as well as the redox-cycling compound plumbagin, which is known to generate reactive oxygen species. Thus, the SenS/SenR system could participate directly or indirectly 
(a)

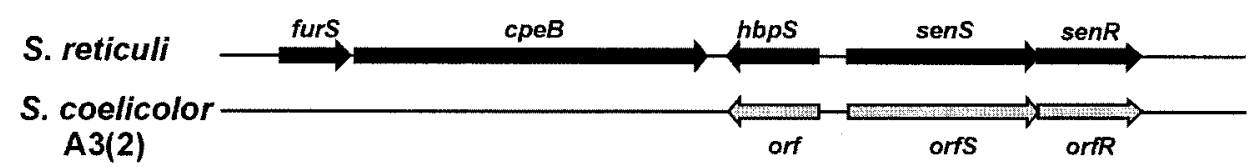

(b)

$$
\begin{aligned}
& \text { up_furs } \\
& \text { up_hbps } \\
& \text { up_furs } \\
& \text { up_hbps } \\
& \text { up_furs } \\
& \text { up_hbps } \\
& \text { up_furs } \\
& \text { up_hbps }
\end{aligned}
$$

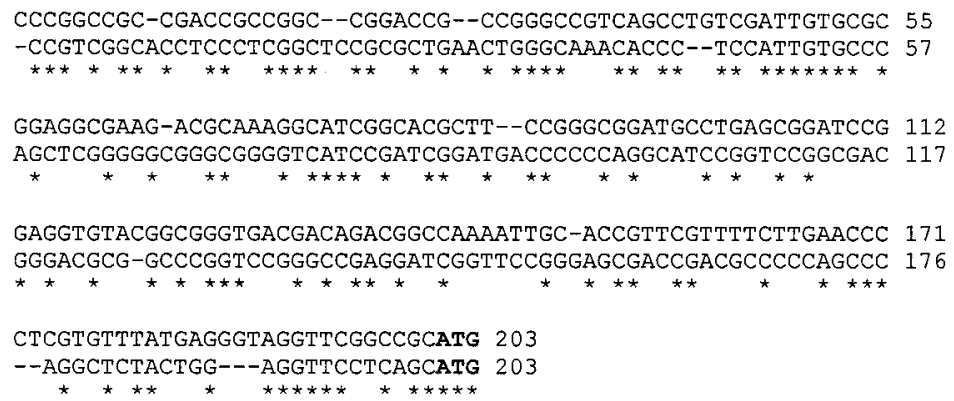

Fig. 6. Gene organization and comparison of DNA regions. (a) The gene organization of furS, cpeB, $h b p S$ and senS/senR on the $S$. reticuli genome is compared with a region from the $S$. coelicolor $A 3(2)$ genome containing the deduced homologues (not studied) orf, orfS and orfR. Homologous genes to furS and $c p e B$ are located elswere in the genome. (b) The upstream DNA region $(0.2 \mathrm{~kb})$ of the $S$. reticuli furS gene (up_furS) was compared with the region $(0.2 \mathrm{~kb})$ upstream of the $S$. reticuli $h b p S$ gene (up_hbpS). The corresponding start codons (ATG) are shown in bold type; identical bases are marked by an asterisk.

in sensing signals generated by redox-triggered events. This conclusion is in line with the observation that the sensitivity to $\mathrm{H}_{2} \mathrm{O}_{2}$ and diamide differs only a little between the WT and the mutant strain.

The upstream regions of $f u r S$ and $h b p S$ (Fig. 6b) both share a few motifs (i.e. ATTGTGC, CATC, AGGTTC and GCATG) that could participate in the interaction with a common regulator protein; this could be SenR (or its modified form) or a so-far-unknown regulatory protein, whose transcription would be predicted to be under the control of SenR. For instance, the two-component system ResD/ResE from B. subtilis influences indirectly the expression of arfM (anaerobic respiration and fermentation modulator), being initially activated by a signal cascade in which the corresponding RR (ResE) activates firstly the synthesis of the redox regulator Fnr (Marino et al., 2001), which subsequently activates the transcription of arfM. Finally, ArfM modulates the expression of genes encoding proteins which further sustain nitrate respiration, such as genes for haem biosynthesis.

Previously, we reported that the presence of the $h b p S$ gene increases the synthesis of the highly active CpeB (Ortiz de Orue Lucana et al., 2004). The catalase and peroxidase activities of $\mathrm{CpeB}$ are also dependent on a properly attached prosthetic haem group (Zou \& Schrempf, 2000). Therefore, it can be suggested that $\mathrm{HbpS}$ could act as a chaperone that binds haem and then delivers it to CpeB, and/or that it might also interact with extracellular, membrane-associated or membrane-integrated protein(s) involved in a signal transduction cascade. The present analysis revealed that HbpS interacts specifically with SenS. Thus, the specific interaction of HbpS with SenS is expected to be of importance for the corresponding signal-transduction cascade in vivo. This conclusion is supported by our previous findings (Ortiz de Orué Lucana et al., 2004) showing that an S. reticuli mutant lacking a functional $\mathrm{HbpS}$ has a considerably reduced level of CpeB. To date, only a few bacterial two-component systems have been shown to be modulated by accessory proteins. In Sinorhizobium meliloti, the protein FixT acts as an inhibitor of the sensor haemoprotein kinase FixL, preventing the production or accumulation of its phosphorylated form (Garnerone et al., 1999). The FixL/J system plays a major role in inducing genes for nitrogen fixation and respiration in response to a low $\mathrm{O}_{2}$ concentration within the nodule. The gene fixT clusters with fixJ/fixL. As shown previously (Ortiz de Orué Lucana et al., 2004), HbpS shares aa identities (38.3\%) to a predicted protein Atu1117 from Agrobacterium tumefaciens. The corresponding gene is located in the direct vicinity of the genes $n w s B$ (former name atu1116), encoding a putative $\mathrm{RR}$, and fixL (former name atu1115), encoding a putative SK, which together are homologous to the two-component system FixL/FixJ (Fischer, 1994). Sensing of the signal and the kinase activity of FixL depends on the spin state of the Fe ion within the haem. A change from a high to low spin state within the Fe ion is induced upon binding of oxygen and this is thought to result in a slight shift in its position within the porphyrin ring (Bauer et al., 1999). Further genes, encoding the two-component systems compB/compA (B. subtilis) and 
comD/comE (Streptococcus pneumoniae), are preceded by comX (Magnuson et al., 1994) and comC (Pestova et al., 1996), respectively, which encode small peptides playing a part in the signal-transduction cascade.

As mentioned above, the sensor kinase FixL utilizes haem as a co-factor to facilitate a conformational change for adapting to redox changes and control the corresponding gene expression. The bound haem group in the HbpS-SenS complex could assist in sensing redox changes. In the future it will be interesting to gain new insights about a special role for SenS/SenR within streptomycetes.

\section{ACKNOWLEDGEMENTS}

We are very grateful to I. Borovok for supporting analysis of the DNA sequence and to T. Schaa for assisting cloning studies and biochemical investigations.

\section{REFERENCES}

Altschul, S. F., Madden, T. L., Schäffer, A. A., Zhang, J., Zhang, Z., Miller, W. \& Lipman, D. J. (1997). Gapped BLAST and PSI-BLAST: a new generation of protein database search programs. Nucleic Acids Res 25, 3389-3402.

Baikalov, I., Schroder, I., Kaczor-Grzeskowiak, M., Grzeskowiak, K., Gunsalus, R. P. \& Dickerson, R. E. (1996). Structure of the Escherichia coli response regulator NarL. Biochemistry 35, 1105311061.

Bauer, C. E., Elsen, S. \& Bird, T. H. (1999). Mechanisms for redox control of gene expression. Annu Rev Microbiol 53, 495-523.

Beck, S. \& Pohl, F. M. (1984). DNA sequencing with direct blotting electrophoresis. EMBO J 3, 2905-2909.

Bentley, S. D., Chater, K. F., Cerdeno-Tarraga, A. M. \& 40 other authors (2002). Complete genome sequence of the model actinomycete Streptomyces coelicolor A3(2). Nature 417, 141-147.

Blake, M. S., Johnston, K. H., Russel-Jones, G. J. \& Gotschlich, E. C. (1984). A rapid, sensitive method for detection of alkaline phosphatase-conjugated anti-antibody on Western-blots. Anal Biochem 136, 175-179.

Blondelet-Rouault, M. H., Weiser, J., Lebrihi, A., Branny, P. \& Pernodet, J. L. (1997). Antibiotic resistance gene cassettes derived from the omega interposon for use in E. coli and Streptomyces. Gene 190, 315-317.

Brian, P., Riggle, P. J., Santos, R. A. \& Champness, W. C. (1996). Global negative regulation of Streptomyces coelicolor antibiotic synthesis mediated by an $a b s A$-encoded putative signal transduction system. J Bacteriol 178, 3221-3231.

Chang, H. M., Chen, M. Y., Shieh, Y. T., Bibb, M. J. \& Chen, C. W. (1996). The CutR/S signal transduction system of Streptomyces lividans represses the biosynthesis of the polyketide antibiotic actinorhodin. Mol Microbiol 21, 1075-1085.

Dower, W. J., Miller, J. F. \& Ragsdale, C. W. (1988). High efficiency transformation of E. coli by high voltage electroporation. Nucleic Acids Res 16, 6127-6145.

Fabret, C., Feher, V. A. \& Hoch, J. A. (1999). Two-component signal transduction in Bacillus subtilis: how one organism sees its world. J Bacteriol 181, 1975-1983.
Fischer, H. M. (1994). Genetic regulation of nitrogen fixation in rhizobia. Microbiol Rev 58, 352-386.

Garnerone, A. M., Cabanes, D., Foussard, M., Boistard, P. \& Batut, J. (1999). Inhibition of the FixL sensor kinase by the FixT protein in Sinorhizobium meliloti. J Biol Chem 274, 32500-32506.

Gasteiger, E., Gattiker, A., Hoogland, C., Ivanyi, I., Appel, R. D. \& Bairoch, A. (2003). ExPASy: the proteomics server for in-depth protein knowledge and analysis. Nucleic Acids Res 31, 3784-3788.

Gold, L., Pribnow, D., Schneider, T., Shninedling, S., Singer, B. S. \& Stormo, G. (1981). Translational initiation in prokaryotes. Annu Rev Microbiol 35, 365-403.

Hall, R. A. (2004). Studying protein-protein interactions via blot overlay or Far Western blot. Methods Mol Biol 261, 167-174.

Higgins, D. G., Bleasby, A. J. \& Fuchs, R. (1992). CLUSTAL V: improved software for multiple sequence alignment. Comput Appl Biosci 8, 189-191.

Hong, H. J., Hutchings, M. I., Neu, J. M., Wright, G. D., Paget, M. S. \& Buttner, M. J. (2004). Characterization of an inducible vancomycin resistance system in Streptomyces coelicolor reveals a novel gene (vanK) required for drug resistance. Mol Microbiol 52, 1107-1121.

Hopwood, D. A., Bibb, M. J., Chater, K. F. \& 7 other authors (1985). Genetic Manipulation of Streptomyces: a Laboratory Manual. Norwich: John Innes Foundation.

Hutchings, M. I., Hoskisson, P. A., Chandra, G. \& Buttner, M. J. (2004). Sensing and responding to diverse extracellular signals? Analysis of the sensor kinases and response regulators of Streptomyces coelicolor A3(2). Microbiology 150, 2795-2806.

Ikeda, H., Ishikawa, J., Hanamoto, K. \& 7 other authors (2003). Complete genome sequence and comparative analysis of the industrial microorganism Streptomyces avermitilis. Nat Biotechnol 21, 526-531.

Laemmli, U. K. (1970). Cleavage of structural proteins during the assembly of the head of bacteriophage T4. Nature 227, 680-685.

Loenen, W. A. \& Blattner, F. R. (1983). Lambda Charon vectors (Ch32, 33, 34 and 35) adapted for DNA cloning in recombinationdeficient hosts. Gene 26, 171-179.

Magnuson, R., Solomon, J. \& Grossman, A. D. (1994). Biochemical and genetic characterization of a competence pheromone from $B$. subtilis. Cell 77, 207-216.

Marino, M., Ramos, H. C., Hoffmann, T., Glaser, P. \& Jahn, D. (2001). Modulation of anaerobic energy metabolism of Bacillus subtilis by arfM (ywiD). J Bacteriol 183, 6815-6821.

Mizuno, T. (1997). Compilation of all genes encoding twocomponent phosphotransfer signal transducers in the genome of Escherichia coli. DNA Res 4, 161-168.

Nielsen, H., Engelbrecht, J., Brunak, S. \& von Heijne, G. (1997). Identification of prokaryotic and eukaryotic signal peptides and prediction of their cleavage sites. Protein Eng 10, 1-6.

Ortiz de Orué Lucana, D. \& Schrempf, H. (2000). The DNA-binding characteristics of the Streptomyces reticuli regulator FurS depend on the redox state of its cysteine residues. Mol Gen Genet 264, 341-353.

Ortiz de Orué Lucana, D., Tröller, M. \& Schrempf, H. (2003). Amino acid residues involved in reversible thiol formation and zinc ion binding in the Streptomyces reticuli redox regulator FurS. Mol Genet Genomics 268, 618-627.

Ortiz de Orué Lucana, D., Schaa, T. \& Schrempf, H. (2004). The novel extracellular Streptomyces reticuli haem-binding protein $\mathrm{HbpS}$ influences the production of the catalase-peroxidase CpeB. Microbiology 150, 2575-2585.

Pao, G. M. \& Saier, M. H., Jr (1995). Response regulators of bacterial signal transduction systems: selective domain shuffling during evolution. J Mol Evol 40, 136-154. 
Parkinson, J. S. (1993). Signal transduction schemes of bacteria. Cell 73, 857-871.

Parkinson, J. S. \& Kofoid, E. C. (1992). Communication modules in bacterial signalling proteins. Annu Rev Genet 26, 71-112.

Pestova, E. V., Havarstein, L. S. \& Morrison, D. A. (1996). Regulation of competence for genetic transformation in Streptomyces pneumoniae by an auto-induced peptide pheromone and a two-component regulatory system. Mol Microbiol 21, 853-862.

Sambrook, J., Fritsch, E. F. \& Maniatis, T. (1989). Molecular Cloning: a Laboratory Manual, 2nd edn. Cold Spring Harbor, NY: Cold Spring Harbor Laboratory.

Schlochtermeier, A., Niemeyer, F. \& Schrempf, H. (1992). Biochemical and electron microscopic studies of the Streptomyces reticuli cellulase (Avicelase) in its mycelium-associated and extracellular forms. Appl Environ Microbiol 58, 3240-3248.

Schmitt, M. P. (1999). Identification of a two-component signal transduction system from Corynebacterium diphtheriae that activates gene expression in response to the presence of haem and haemoglobin. J Bacteriol 181, 5330-5340.

Sheeler, N. L., MacMillan, S. V. \& Nodwell, J. R. (2005). Biochemical activities of the absA two component system of Streptomyces coelicolor. J Bacteriol 187, 687-696.

Sola-Landa, A., Moura, R. S. \& Martin, J. F. (2003). The twocomponent PhoR-PhoP system controls both primary metabolism and secondary metabolite biosynthesis in Streptomyces lividans. Proc Natl Acad Sci U S A 100, 6133-6138.
Stojiljkovic, I., Evavold, B. D. \& Kumar, V. (2001). Antimicrobial properties of porphyrins. Expert Opin Investig Drugs 10, 309-320.

Strohl, W. R. (1992). Compilation and analysis of DNA sequences associated with apparent streptomycete promoters. Nucleic Acids Res 20, 961-974.

Tsujibo, H., Hatano, N., Okamoto, T., Endo, H., Miyamoto, K. \& Inamori, Y. (1999). Synthesis of chitinase in Streptomyces thermoviolaceus is regulated by a two-component sensor-regulator system. FEMS Microbiol Lett 181, 83-90.

Vara, J., Lewandowska-Skarbek, M., Wang, Y.-G., Donadio, S. \& Hutchinson, C. R. (1989). Cloning of genes governing the deoxysugar portion of the erythromycin biosynthesis pathway in Saccharopolyspora erythraea (Streptomyces erythreus). J Bacteriol 171, 5872-5881.

Villarejo, M. R., Zamenhof, P. J. \& Zabin, I. (1972). Betagalactosidase. In vivo-complementation. J Biol Chem 247, 22122216.

Zou, P. \& Schrempf, H. (2000). The heme-independent manganeseperoxidase activity depends on the presence of the C-terminal domain within the Streptomyces reticuli catalase-peroxidase CpeB. Eur J Biochem 267, 2840-2849.

Zou, P., Borovok, I., Ortiz de Orué Lucana, D., Müller, D. \& Schrempf, H. (1999). The mycelium-associated Streptomyces reticuli catalase-peroxidase, its gene and regulation by FurS. Microbiology 145, 549-559. 